\title{
One Phase Moving Boundary Problem
}

\author{
P. Kanakadurga Devi, V. G. Naidu
}

\begin{abstract}
In this paper we introduced a variable time step method to obtain interface to moving boundary problem for Slab and Sphere. We present the basic difficulty, apart from the need to find the moving boundary, that there is no domain for the space variable. This difficulty is handled by the age old principles of basic mathematics. Naturally, giving symbolic names to the unknowns develop equations involving them and solve it using the conditions of the problem. High order accurate initial time step sizes for given space step size are obtained with the help of Green's theorem. The Subsequent time steps are obtained by an iterative scheme. This variable time step method handles Dirichlet's problem of freezing or melting of a Slab and spherical droplet.
\end{abstract}

Keywords: interface, Finite difference method, Crank-Nicolson scheme, stefan problem, variable time step.

\section{INTRODUCTION}

If thin rod of a solid material is melted by suppling heat, at one end, melting takes and the interface keeps moving.

When a spherical ball is frozen (or melted), the equation for the heat diffusion along a radial line is governed by [1].The spherical polar coordinates governing equations are reduced to

$$
\begin{aligned}
& \frac{\partial T}{\partial t}=\frac{\partial^{2} T}{\partial x^{2}}, \quad 0<x<s(t) \\
& T(0, t)=-1 \\
& T(s(t), t)=0 \\
& s(0)=0 \\
& \frac{\partial T}{\partial x}=\beta(1-x) \frac{d s}{d t}
\end{aligned}
$$

Diffusion coefficient is normalized to unity and diffusion of heat beyond $s(t)$ is assumed to be not taking place. Stefan number $\beta$ is a constant depending on the density, specific heat and latent heat of the material. The basic methodology will be developed in section 2.In section 3, we derive two equations involving the two unknowns using Green's theorem for the given problem and obtained $T_{1,2}$ to start the solution procedure. Once we do this, we can find $T_{1, \mathrm{a}}, T_{2, \mathrm{a}}$ provided $k_{\mathrm{a}}$. This can be continued to solve the diffusion equation for $n=3,4,5 \ldots$. The number of points

Revised Manuscript Received on December 30, 2019.

* Correspondence Author

P. Kanakadurga Devi*, Department of Mathematics, MLR Institute of Technology, Hyderabad, India. E-mail:durga.thulasi@gmail.com

V. G. Naidu, Adama Science and Technology University, PO Box-1888, Ethiopia. E-mail:naidoovedam@gmail.com

(C) The Authors. Published by Blue Eyes Intelligence Engineering and Sciences Publication (BEIESP). This is an open access article under the CC BY-NC-ND license (http://creativecommons.org/licenses/by-nc-nd/4.0/) along the line parallel to $x$-axis increases one by one for increasing $n$. In section 4 , iterative procedure to find $k_{n n}$, for $n \geq 3$ and the computational procedure as an algorithm is given in this section. Consideration of the convergence to find $k_{n}$ is done in section 5 and an example is given in section 6. The well known one phase problem of freezing (or melting) of a spherical droplet is given as an example.

Stewartson and Waechter [10] obtained solution by asymptotic expansion of the variables and discussed the results qualitatively. Similar exercise was done by Soward [9]. Davis and Hill [1] is one of the few researchers, who gave quantitative details about the time taken for the interface to reach the centre. Numerical Methods to obtain approximate solution relevant to our work, was first introduced by Douglas and Gallie [2]. Although no specific results were presentedfor a fixed space step, they used variable time step sizes to track the front. Gupta and Kumar [3] and Marshall [6] have subsequently improved the iterative procedure of [2] for finding the time step. Kutluay [5] obtained numerical solution of a specific problem with variable space grid; even these front tracking methods have made certain transformations of the original problem [11-12].

\section{BASIC FRAME WORK OF COMPUTATIONAL METHODOLOGY}

For a fixed space step size, the time intervals needed for the interface can be fine. If $T_{i, n}$ is the temperature at $x_{i}=i h, t_{n n}=\sum_{l=1}^{n} k_{1} ; T_{i, n}=0, i \geq n ; i=n$ gives a temperature on the interface.

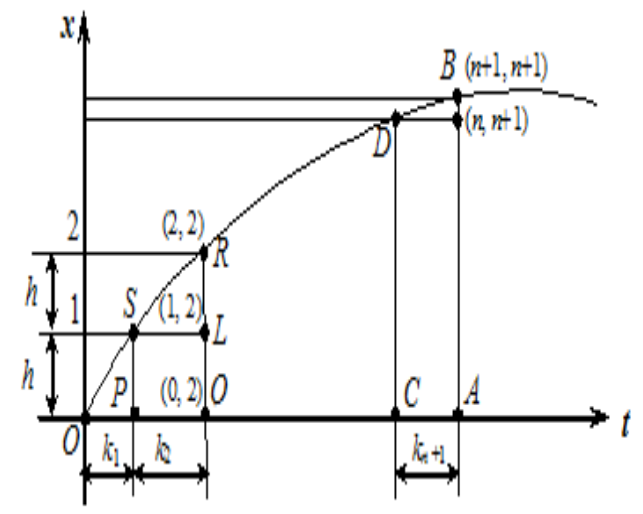

Fig. 1. Moving boundary with variable time step.

Using theCrank-Nicolson scheme the diffusion equation becomes

$\frac{T_{i, n+1}-T_{i, n}}{k_{n+1}}=\frac{1}{2 h^{2}}\left[\left(T_{i-1, n+1}-2 T_{i, n+1}+T_{i+1, n+1}\right)+\left(T_{i-1, n}-2 T_{i, n}+T_{i+1, n}\right)\right]$

Sometimes we need the fully implicit scheme (for manipulations at a later stage) as 


\section{One Phase Moving Boundary Problem}

$\frac{T_{i, n+1}-T_{i, n}}{k_{n+1}}=\frac{1}{h^{2}}\left(T_{i-1, n+1}-2 T_{i, n+1}+T_{i+1, n+1}\right)$

To enable us using this scheme, we need to know $\mathrm{T}$ at three points,(0,2), (1,2) and (2,2)(see figure1). Of these three; $T_{0,2}$ is given in the problem, $T_{2,2}=0$ and $T_{1,2}$ is not known. To know these starting ingredients, we need to find $k_{1}$ and $k_{2}$.

This is a first order approximation in $\mathrm{x}$ and $\mathrm{t}$. Apply the Green's theorem in the region OPS in the first cell. In the process, we need the second degree polynomial to the interface passing through the points $(0,0),\left(k_{1}, h\right)$ and $\left(k_{1}+k_{2}, 2 h\right)$ as

$s(t)=\frac{t h}{k_{1}}+\frac{t h\left(t-k_{1}\right)\left(k_{1}-k_{2}\right)}{k_{1} k_{2}\left(k_{1}+k_{2}\right)} \quad$ (Newton divided difference polynomial)

$\frac{d s}{d t_{t=0}}=\dot{s}(0)=h \frac{\left[k_{2}^{2}-k_{1}^{2}+2 k_{1} k_{2}\right]}{k_{1} k_{2}\left(k_{1}+k_{2}\right)}=\frac{1}{\beta(1-x)} T_{x(0,0)}$

$\frac{d s}{d t_{t=t_{1}}}=s^{s}\left(t_{1}\right)=h \frac{\left\lfloor k_{2}^{2}+k_{1}^{2}\right\rfloor}{k_{1} k_{2}\left(k_{1}+k_{2}\right)}=\frac{1}{\beta(1-x)} T_{x(\mathbb{1}, 1)}$

$\frac{d s}{d t_{t=t_{2}}}=s^{\prime}\left(t_{2}\right)=h \frac{\left\lfloor k_{1}^{2}-k_{2}^{2}+2 k_{1} k_{2}\right\rfloor}{k_{1} k_{2}\left(k_{1}+k_{2}\right)}=\frac{1}{\beta(1-x)} T_{x(2,2)}$

We know that by Green's Theorem

$$
\oiint_{R}\left[T_{x x}-T_{t}\right] d x d t=0 \Rightarrow \int_{C}\left[T_{x} d t+T d x\right]=0,
$$

Where $\mathrm{c}$ is the boundary of $\mathrm{R}$ and $c=O P \cup P S \mathrm{U} S O$

$I_{1}=\int_{O P}\left[T_{x} d t+T d x\right]=\int_{0}^{k_{1}}\left[T_{x} d t\right]=\frac{k_{1}}{2}\left[\left.T_{x}\right|_{0}+\left.T_{x}\right|_{P}\right]$

Therefore $I_{1}=\frac{k_{1}}{2}\left[-\frac{g\left(k_{1}\right)}{\mathrm{h}}+\beta(1-h) h \frac{\left[k_{2}^{2}-k_{1}^{2}+2 k_{1} k_{2}\right]}{k_{1} k_{2}\left(k_{1}+k_{2}\right)}\right]$

Here, we approximated $\left.T_{x}\right|_{p}$ by $\frac{T_{s}-T_{F}}{\hbar}=\frac{0-g\left(k_{1}\right)}{\hbar}$,

$\left.T_{x}\right|_{0}=\beta(1-x) s^{\prime}(0)$ and

$l_{2}=\int_{p S}\left[T_{x} d t+T d x\right]=\int_{0}^{\mathrm{h}}[T d x]=\frac{\mathrm{h}}{2}\left[\left.T\right|_{p}+\left.T\right|_{S}\right]$

Thus $l_{2}=\frac{\mathrm{h}}{2} g\left(k_{1}\right)\left(\mathrm{T}_{s}=0\right.$ being on the interface $)$

$\operatorname{Now}_{a}=\int_{S O}\left[T_{x} d t+T d x\right]=\int_{k_{1}}^{0}\left[T_{x} d t\right](T=0$ ats $)$

$$
I_{\mathrm{a}}=\int_{k_{1}}^{0}\left[\beta(1-x) \frac{d s}{d t} d t\right]=-\frac{\beta h}{2}(2-\mathrm{h})
$$

Thus $I_{a}=-\frac{\beta h}{2}(2-\mathrm{h})$

By the green's theorem $I_{1}+I_{2}+I_{\mathrm{a}}=0$

$\frac{k_{1}}{2}\left[-\frac{g\left(k_{1}\right)}{h}+\beta(1-h) h \frac{\left\lfloor k_{2}^{2}-k_{1}^{2}+2 k_{1} k_{2}\right\rfloor}{k_{1} k_{2}\left(k_{1}+k_{2}\right)}\right]$

$+\frac{h}{2} g\left(k_{1}\right)-\frac{\beta h}{2}(2-h)=0$

We thus have one relation involving two unknowns $k_{1}$ and $k_{2}$ as

$g\left(k_{1}\right) k_{2}\left(k_{1}+k_{2}\right)\left(h^{2}-k_{1}\right)-\beta h^{2}(2-h)\left(k_{1}^{2}+k_{2}^{2}\right)=0$

To derive another equation involving $k_{1}$ and $k_{2}$, we have from

Stefan's condition at $(2,2)$ gives

$\frac{2 \beta h^{2}(1-2 h)}{k_{2}}=4 T_{1_{2} 2}-g\left(t_{2}\right)$

At $(1,2)$, from $(7) T_{1,2}=\frac{k_{2} g\left(t_{2}\right)}{h^{2}+2 k_{2}}$
Using the equation (13) in (12) we get

Thus

$k_{2} g\left(t_{2}\right)\left(2 k_{2}-h^{2}\right)+2 \beta h^{2}(1-2 h)\left(2 k_{2}+h^{2}\right)=0$

We can solve (11) and (14) to find $k_{1}$ and $k_{2}$ using the relation (13).

We have $(n+1)$ unknowns

$\left(T_{1}, T_{2}, T_{a x} \ldots, T_{n}, k_{n+1}\right.$ at $\left.t=t_{n+1}\right)$ with $n$ equations coming from the Crank-Nicholson scheme. Much needed another equation comes from the Stefan condition at $(n+1, n+1)$ as

$\beta(1-n h) \frac{h}{k_{n+1}}=\left(T_{n-1, n+1}-4 T_{n_{n} n+1}+3 T_{n+1} n+1\right) / 2 h$

This can be written as:

$4 T_{n_{n} n+1}-T_{n-1, n+1}=2 \beta(1-n h) \frac{h^{2}}{k_{n+1}}$

With $i=n$ in the system (7), we have

$\frac{T_{m, n+1}-T_{m n}}{k_{n+1}}=\frac{\left(T_{m+1, n+1}-2 T_{m, n+1}+T_{m-1, n+1}\right)}{\hbar^{2}}$

On simplifying to (In fact, we cannot use Crank- Nicolson scheme at $(n, n+1)$ since the point outside the domain occurs in the difference equation)

Thus $T_{n n+1}=\frac{k_{n+1}}{\left(h^{2}+2 k_{n+1}\right)} T_{n-1, n+1}$

This, when substituted in (16), we get

$T_{n-1, n+1}=\frac{2 \beta h^{2}(1-n h)\left(2 k_{n+1}+h^{2}\right)}{k_{n+1}\left(h^{2}-2 k_{n+1}\right)}$

Using (17) in (16) we get $T_{n_{n} n+1}=\frac{2 \beta h^{2}(1-n h)}{\left(h^{2}-2 k_{n+1}\right)}$

Considering (17) as a quadratic in $k_{n+1}$, the positive root can be obtained as:

$k_{n+1}=\frac{h^{2}}{4 T_{n-1 n+1}}\left[T_{n-1, n+1}-4 \beta(1-n h)-\sqrt{\left(T_{n-1 n+1}+4 \beta(1-n h)\right)^{2}+16 \beta(1-n h) T_{n-1, n+1}}\right]$

Choosing an initial approximation fork $k_{n+1}$; calculate $T_{n n+1}$ using (18). Solve the finite difference equations for $i=1,2 \ldots$ $n-1$ with $T_{n_{2} n+1}$ as a boundary condition. From the resultant value for $T_{n-1, n+1}$, obtain $k_{n+1}$ from the relation (19). Calculate $T_{n_{n}+1}$ using (18) and solve the difference equations as earlier. Repeat the process until the desired degree of accuracy occurs.

\section{CONVERGENCE}

If $k_{n+1}$ is chosen on the manifold given by equation (15) for every iteration, convergence of the solution of the method is assured by Koneru and Lalli [4]. But to reduce the computational effort, we have solved the system by Thomas algorithm. We have to make sure that $k_{n+1}$, after each such solution, has to be chosen satisfying (15), equivalently (17) and (18). Thus we calculate $k_{n+1}$ using (19) satisfying (17) and obtain $T_{n}$ from (18) with this $k_{n+1}$ and use it as a boundary condition. After choosing $k_{n+1}$ to start the iteration process, some value of $T_{n}$ exists and lies on the manifold. Any starting value for $k_{n+1}$ works, as this implies any starting values for $T_{n-1}$ and $T_{n}$ satisfying (17) and (18);

Published By: 
and that means (15). We have to first calculate $T_{n}$ and solve for $T_{n-1}, T_{n-2}, T_{n-9, \ldots x}, T_{2}, T_{1}$.

\section{EXAMPLES}

We obtained the numerical solution using the algorithm of section 2.Time for the interface to reach the centre with varying step sizes and for several values of the Stefan constant $(\beta)$ are presented in the table 1. Results from Davis and Hill [1] with first three terms of the expansions are given in the last column. These obtained present results are compared well with ref. [1].

Table 1.Time taken for the interface to reach the centre for $g(t)=-1$

\begin{tabular}{c|l|llll|}
\hline \multicolumn{5}{c|}{ Present Results for different ralues of $\beta$} \\
\hline$\beta$ Bh & 0.04 & 0.02 & 0.01 & 0.005 & Results of ref. $[1]$ \\
\hline 0.25 & 0.1219 & 0.1270 & 0.1260 & 0.1265 & 0.131 \\
0.5 & 0.1826 & 0.1805 & 0.1800 & 0.1799 & 0.190 \\
1.0 & 0.2781 & 0.2760 & 0.2753 & 0.2752 & 0.290 \\
5.0 & 0.9690 & 0.9678 & 0.9671 & 0.9667 & 0.987 \\
\hline 10.0 & 1.8088 & 1.8092 & 1.8087 & 1.8084 & 1.83 \\
\hline 50.0 & 8.4695 & 8.4851 & 8.4880 & 8.4886 & 8.50 \\
\hline
\end{tabular}

The interface for the one phase sphere problem has been presented graphically with $\beta=1,10,50$ in figure 2 .The impact of Stefan number $\boldsymbol{\beta}$ is clearly seen from the graphs drawn.

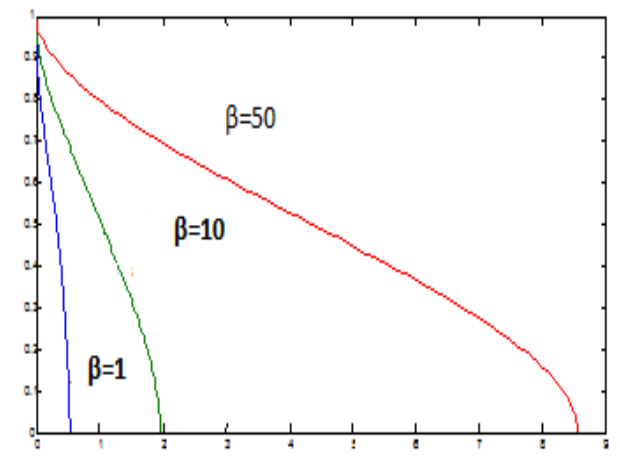

Fig 2. Interface for the sphere proble

It may be noted that even if the freezing process on the surface is time dependent, our algorithm works well without any difficulty. Indeed, this statement applies to all the problems considered by us. The computational method to obtain an approximate solution to the classical two-phase Stefan problem with quadratic polynomial approximation to the front has been discussed in [8].

\section{ACKNOWLEDGMENT}

Authors wish to thank Prof. S.R. Koneru for his support and performing work in this paper.

\section{REFERENCES}

1. Davis G.B and Hill J.M. (1982)A Moving Boundary problem for the sphere. I.M.AJournal of Applied Mathematics, 29, 99-111.
2. Douglas Jr Jim and JrGallie T.M. (1955) On the numerical integration of parabolic differential equations subject to a moving boundary condition. Duke Math. J., 22, 557-571.

3. Gupta P.S. and Kumar D. (1980)A modified variable time step method for one-dimensional Stefan problem. Comp. Math. Appl. Mech. Engineering, 23, 101-108.

4. Koneru S.R. and Lalli B.S. (1971)On Convergence of iteration for fixed points of repulsive type,Canad. Math. Bulletin, 14, 353-357.

5. Kutluay S., Bahadir A.R. and Ozdes A. (1997)The numerical solution of one phaseclassical Stefan problem,J. Comput. Appl. Math, 81, 135-144.

6. Marshall Guillermo. (1986)A front tracking method for one-dimensionalmoving boundary problems, SIAM J. Sci. Stat Comput.,7, 252-263.

7. Mitchel S. L. and Vynnycky. (2009)Finite difference method with increased accuracy and correct initialization for 1-dimensional Stefan problem. Applied Mathematicsand Computation, 215, 1609 - 1621.

8. P. Kanakadurga Devi, D., Naidu, V.G. (2015). A New Finite Difference Front Tracking Method for Two Phase 1-D Moving Boundary Problems. ScienceDirect (Elsevier) www.elsevier.com/locate/procedia, Procedia Engineering, 127, 1034-1040.

9. Soward A.M. (1980) A unified approach to Stefan problems for spheres andcylinders.Proc.Roy.Soc.,A 373, 131-147.

10. Stewartson K. and Waechter R.T. (1976)on Stefan's problem for sphere. Proc. Roy. Soc. A, 348, 415-428.

11. Kanakadurgadevi P, Naidu VG and Koneru SR, "Finite Difference method for one dimensional Stefan problem", Journal of Advanced Reaserch in Dynamical and Control System, No.3,2018 pp.1245-1252.

12. Kanakadurgadevi P, Naidu VG \& Koneru SR, "Free and moving boundary problems for heat and mass transfer", International Journal of Engineering and Technology, No.7, 2018, pp.18-19.

\section{AUTHORS PROFILE}

Name: Dr. Kanaka Durga Devi Pathella

Address for correspondence: Plot No. 305,

Maheswara Residency, Sai Bhaghavan Sa Beeramguda, R.C.Puram, Medak District Durga. Email(s) and contact number(s): thulasi@gmail.com and 919346916005

Date of Birth: 20-07-1984

Department: Applied Mathematics

Academic Qualification

\begin{tabular}{|c|c|c|c|c|}
\hline S.No. & Qualification & Institution & year & Percentage \\
\hline 1 & $\begin{array}{c}\text { Ph.D(Numerical } \\
\text { Analysis) }\end{array}$ & $\begin{array}{c}\text { S.V.University, } \\
\text { Tirupati }\end{array}$ & 2012-2016 & Awarded \\
\hline 2 & $\begin{array}{l}\text { M.Phil(Numerical } \\
\text { Analysis) }\end{array}$ & $\begin{array}{c}\text { S.V.University, } \\
\text { Tirupati }\end{array}$ & 2010-2012. & 72 \\
\hline 3 & $\begin{array}{l}\text { M.Sc(Applied } \\
\text { Mathematics) }\end{array}$ & $\begin{array}{c}\text { Andhra } \\
\text { University, } \\
\text { Vizag }\end{array}$ & 2004-2006 & 70 \\
\hline 4 & $\begin{array}{l}\text { B.Sc(Computer } \\
\text { science) }\end{array}$ & $\begin{array}{c}\text { Bapatla } \\
\text { College of Arts } \\
\text { and Science, } \\
\text { Bapatla }\end{array}$ & 2001-2004 & 72 \\
\hline 5 & Intermediate & $\begin{array}{c}\text { Balaji junior } \\
\text { college, Ponnur }\end{array}$ & 1999-2001 & 85 \\
\hline 6 & S.S.C & $\begin{array}{l}\text { Z.P.H.School, } \\
\text { Ponnur }\end{array}$ & 1998-1999 & 77 \\
\hline
\end{tabular}

Ph.D thesis title: Front Tracking Methods For One And Two Phase Stefan Problems

Guide's Name: Dr. G. Viswanatha Reddy

Institute/Organization/University: Sri Venkateswara University

Year of Award: March-2016

Work experience 


\section{One Phase Moving Boundary Problem}

\begin{tabular}{|c|c|c|c|c|}
\hline S.No. & $\begin{array}{c}\text { Positions } \\
\text { held }\end{array}$ & Name of the Institute & From & To \\
\hline 1 & $\begin{array}{c}\text { Assoc. } \\
\text { Prof. }\end{array}$ & MLR Institute of Technology & 2017 & \\
\hline 2 & Asst. Prof. & Vignan University,Guntur & 2015 & 2017 \\
\hline 3 & Asst. Prof. & Vignan University,Guntur. & 2009 & 2010 \\
\hline 4 & Asst. Prof. & $\begin{array}{c}\text { Gudlavalleru Engineering } \\
\text { College,Gudlavalleru. }\end{array}$ & 2007 & 2009 \\
\hline
\end{tabular}

10. II International Conference on Applications of Fluid Dynamics, $21^{\text {st }}$ $-23^{\text {rd }}$, July 2014 at department of Mathematics, Sri Venkateswara University, Tirupati.

11. National Conference on Applications of Mathematics in Engineering, Physical and Life Sciences, 7-9, December 2012 in Sri Venkateswara University, Tirupati.

12. Two-week ISTE WORKSHOP on Introduction to Research Methodologies conducted by Indian institute of Technology Bombay from $25^{\text {th }}$ June to $04^{\text {th }}$ July, 2012 in Gokaraju Rangaraju Institute of Engineering and Technology, Hyderabad.

13. Faculty development program (FDP) from $10^{\text {th }}$ July to $15^{\text {th }}$ July 2009 in VIGNAN UNIVERSITY, Guntur.

\section{RESEARCH ACTIVITY}

Software Proficiency: Languages : FORTRAN, C, .NET

Professional Recognition/ Award/ Prize/ Certificate, Fellowship received by the applicant.

i. Selected as Associative fellow in AP science congress

ii. Got $\mathbf{1}^{\text {st }}$ rank in N U CET-2004 in Mathematics.

iii. FET (Faculty Eligibility Test) qualified in 2012.

iv. Completed Rastrabhasha Praveena in Hindi.

\section{Publications:}

Number of Publications: 7

1. Kanakadurga Devi P., Naidu.V.G. (2018). One Dimensional Two Phase Problem. IEEE Xplore.

2. Kanakadurga Devi P., Naidu.V.G. (2018). Free and Moving Boundary Problems of Heat and Mass Transfer . International Journal of Engineering \& Technology, 7 (3.27) (2018) 18-19.

3. Kanakadurga Devi P., Naidu.V.G. (2018). Finite difference method for One dimensional Stefan Problem journal of Adv Research in Dynamical \& Control systems, Vol. 10, 02-Special Issue, 2018.

4. Kanakadurga Devi P., Naidu.V.G. (2015). A New Finite Difference Front Tracking Method for Two Phase 1-D Moving Boundary Problems. Procedia Engineering, 127, 1034-1040.

5. Kanakadurga Devi P., G. Viswanath Reddy and Naidu.V.G. (2015). A Front Tracking Method for two phase classical 1-D stefan problem. International Journal of Scientific and Innovative Mathematica Research (IJSIMR), Volume 3, Special Issue 3, July 2015, PP 1000-1006, ISSN 2347-307X.

6. Kanakadurga Devi P., Naidu.V.G. and G. Viswanath Reddy (2015). A New Computational method for single phase Classical 1-D Stefan Problem. International Journal of Advanced Scientific and Technical Research, Volume 21 Issue 5, March-April 2015, ISSN 2249-9954.

7. Kanakadurga Devi P., Naidu.V.G. and G. Viswanath Reddy (2015). A New method for Single phase 1-D Stefan Problem. International Journal of Mathematical Archive-6(2), 2015, ISSN 2229-5046.

Participation/Presentation of papers in Conferences: 10

1. International Conference on Smart System and Inventive Technology (ICSSIT 2018), organized by Francis Xavier Engineering College, during December 13-14, 2018 at Tirunelveli, Tamilnadu, India.

2. Presented and selected for Best poster award in the Andhra Pradesh Science Congress held at Yogi Vemana University during 9-11 November, 2018.

3. Quality Improvement Program conducted by Nation Institute of Technical Teachers Training \& Research in MLR institute of technology from $2^{\text {nd }}$ to $7^{\text {th }}$ Jult 2018.

4. World summit on advances in science, engineering and technology, university of Cambridge, united kingdom, one phase 1-d moving boundary problem for sphere 2018.

5. Two days Research Workshop at IIIT, Hyderabad on $26-27^{\text {th }}$ August 2017.

6. International Workshop and Conference on Mathematical Computer Engineering (ICMCE-2016), December 16-17, 2016, organized by the school of Advanced Sciences, VIT University, Chennai.

7. International Workshop and Conference on Analysis and Applied Mathematics (IWCAAM)-2016, June 06-10, 2016, at department of Mathematics, National Institution of Technology, Tiruchirappalli.

8. International Conference on Computational Heat and Mass Transfer (ICCHMT)-2015, 30 Nov-2 Dec 2015, at department of Mathematics, National Institution of Technology, Warangal.

9. 102nd Indian Science Congress to be held at Mumbai University from 3rd to 7th January 2015. Mathematics, AdamaScience Technology University, Ethiopia.

I have completed my $\mathrm{Ph}$. D degree in Applied Mathematics, thesis entitled "Study of some problems in Magneto-hydrodynamic (MHD) flows", from Indian Institute of Technology Bombay, India, in 1989. Since then, I have been teaching for the last 30 years and working on numerical solutions of Boundary Value Problems, which arise in the calculation of Fluid Dynamics.

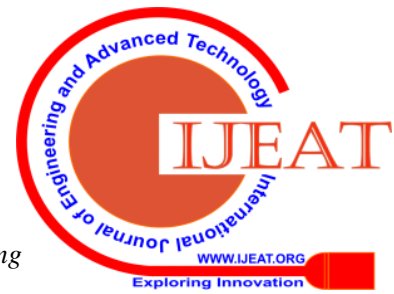


In the recent research work, aim is to introduce a new Computational method to obtain approximate solution to one phase Stefan problems. Several methods exist, but each of them is mostly specific problem oriented and is not general enough to be applicable to a wide range of problems. The work developed a front tracking finite difference method with variable time step. This variable time step method was suggested earlier; but without a well-defined complete methodology. For a fixed space step, first two time steps are obtained using collocation and/or Green's theorem of vector calculus. Subsequent step sizes are obtained by an iterative process with assured convergence. For a non-thermal diffusion, Stefan condition is of implicit nature. For such class of two point boundary value problems, method of bisection is efficient to obtain their solutions. The methods are illustrated by presenting three examples one of which is much discussed oxygen diffusion problem, which is published. The procedure is general enough to be applicable to a broad class of moving boundary problems.

Publications:Published about $\mathbf{1 8}$ papers in National and International journals.

Attended/conducted 20 Workshops/conferences/seminars

Professional Membership: Life member of "ISTE \& APSMS

http://www.mathsnvision.com/

Declaration: I, the undernoted signatory, hereby certify that the information provided above and in the attached documents is correct. I understand that any deliberate falsehood could lead to termination of my employment contract with the University and that any offer of employment is subject to the receipt of satisfactory references and security check. 